\title{
Production of Pelletized Fuel from Biodiesel- Production Wastes: Oil Palm Fronds and Crude Glycerin
}

\author{
Orathai Chavalparit $^{1, a}$, Maneerat Ongwandee ${ }^{2, b}$, and Krittiporn Trangkaprasith ${ }^{1, c}$ \\ 1 Department of Environmental Engineering, Faculty of Engineering, Chulalongkorn University, Bangkok \\ 10330, Thailand \\ 2 Faculty of Engineering, Mahasarakham University, Mahasarakham 44150, Thailand \\ E-mail: aOrathai.C@Chula.ac.th (Corresponding author), bmaneerat.o@msu.ac.th, cbowl_17@hotmail.com
}

\begin{abstract}
Biomass from agricultural residue is regarded as an important source of renewable energy in Thailand due to tremendous annual production. One of the country's largest and most available crop residues is obtained from plantations of oil palm that are used mainly to supply biodiesel feedstock. Thus, this study was aimed to investigate the potential of using oil palm fronds and crude glycerin, a by-product from biodiesel production, to produce pelletized fuel, which is expected to help the biodiesel-processing industry achieve zero waste. The crude glycerin was combined with ground fronds as a biomass binder. The glycerin content, ranging from 19 to $45 \%$ (by weight), enhanced the heating value of the oil palm fronds from $17.2 \mathrm{MJ} / \mathrm{kg}$ (no addition of glycerin) to 17.8-20.4 $\mathrm{MJ} / \mathrm{kg}$. The fuel properties, which were examined by the proximate and ultimate analyses, comply with the quality demands of pelletized fuel suggested by the European Biomass Industry Association. Although the combustion ash content was found to be higher than the criterion, the ash chemical composition was found to be suitable for being used as a cement-replacement material. The result of preconditioning the crude glycerin with $\mathrm{pH}$ adjustment indicated that the preconditioning did not appear to have the effect on the fuel heating of the palm frond pellets.
\end{abstract}

Keywords: Pelletized fuel, oil palm fronds, glycerin, heating value.

ENGINEERING JOURNAL Volume 17 Issue 4

Received 28 January 2013

Accepted 3 April 2013

Published 1 October 2013

Online at http://www.engj.org/

DOI:10.4186/ej.2013.17.4.61 


\section{Introduction}

The utilization of biomass for heating and power generation has received great attention due to the fossil fuel depletion crisis and concerns over the climate change issue. In Thailand, biomass is considered to be an important source of renewable energy in household and industrial sectors contributing to $17.1 \%$ of the total energy consumed in the nation [1]. The biomass is mostly obtained from a variety of agricultural stocks and residues such as sugarcane, rice, cassava, and oil palm. Despite the increasing use of biomass in the country, approximately 59 million tons of agricultural residues were left unused in 2009, which is equivalent to a potential energy amount of $5 \times 10^{17} \mathrm{~J}$ [2]. The biomass materials have low bulk density and high moisture content. These undesirable properties cause several major hindrances for biomass collection, transportation, and storage. One of the solutions is to pelletize the bulky biomass materials. Pellets are often favored for fuel applications because of their enhanced physical properties as well as being easy to utilize and store. Many agricultural residues have been pelletized and examined for fueling properties. They include cotton waste, wheat straw, bean pod, cereal husk, palm fiber, palm kernel cake, empty fruit bunch, etc. [3-5]. Recent studies have focused on improvement of the pelletized fuel properties, which are influenced by many factors such as particle size, moisture content, type of binders, pelletizing processes, including pelletizing pressure, temperature, and pretreatment of raw material [6-11].

The Thai government has been promoting domestic production of biodiesel (methyl esters) as a substitute diesel fuel. Mostly, the commercial scale biodiesel plants use crude palm oil as raw material because of its large production crop yield [12]. Therefore, oil palm plantation areas in Thailand have been increasingly expanded resulting in a tremendous amount of oil palm crop residues. The Department of Alternative Energy Development and Efficiency estimated that 2.2 tons of oil palm fronds were produced in 2009 [2]. The production of biodiesel by a transesterification reaction method also produces a large quantity of crude glycerin, which is known as a biodiesel by-product [12]. The average production of one cubic meter of biodiesel generates approximately $140 \mathrm{kgs}$ of glycerin. The production of glycerin from the Thai biodiesel industry was expected to be $9 \times 10^{5}$ liters/day in 2012 [13]. Currently, glycerin from large-scale biodiesel plants in Thailand is mostly disposed of by sending it to cement-processing plants that use the liquid glycerin as an alternative fuel for their kilns. However, the owners of the biodiesel plants are asked to pay for this glycerin-destroying application. Although the crude glycerin can be sold to soap or fertilizer industries, its high heating value has drawn attraction as an energy source. Glycerin has a heating value of $25 \mathrm{MJ} / \mathrm{kg}$ compared with $41 \mathrm{MJ} / \mathrm{kg}$ of fuel oil, while oil palm crop fronds have a heating value of $17 \mathrm{MJ} / \mathrm{kg}$ [13-15]. To develop an alternative source of energy from biodiesel-production residues and to promote a zero waste approach for the biodiesel industry, this study aimed to use oil palm fronds and crude glycerin as the raw materials for production of pelletized fuel. The effects of the raw material ratio, crude glycerin type, glycerin content, and glycerin preconditioning on the fuel properties were investigated and they were compared with quality demands of pelletized fuel.

\section{Experimental}

\subsection{Raw Material Preparation and Analytical Methods}

The fresh oil palm fronds were sun-dried for a couple of days to reduce the moisture content from $78 \%$ to below $20 \%$. The dried fronds were ground with a high-speed grinder and then were sieved through a 2-mm screen. The ground fronds with particle size less than $2 \mathrm{~mm}$ were selected for pelletization. The ground fronds were kept in air-tight plastic bags prior to experimentation. In this study crude glycerin was obtained from two biodiesel-processing plants. Both biodiesel plants employ a transesterification reaction method with alkali catalysis. Glycerin 1 was obtained from a community biodiesel-processing plant that used batch reactors. Feedstock was used-cooking oil and palm oil and a base catalyst was caustic soda $(\mathrm{NaOH})$. The crude glycerin was simply separated from methyl esters and water by gravitational settling, and it did not undergo an acid treatment and glycerin purifying process. Thus, Glycerin 1 still contained impurities such as residual methyl esters, catalyst, methanol, and water, to some degree. In contrast to Glycerin 1, Glycerin 2 was obtained from an industrial-scale, continuous-mode biodiesel plant using palm oil as a feedstock and $\mathrm{KOH}$ as a base catalyst. The crude glycerin, after separating from methyl ester, was neutralized with a sulfuric acid to form a precipitate $\mathrm{KSO}_{4}$, which can be sold as fertilizer feedstock. Due to employment of 
the more efficient biodiesel-processing technology, Glycerin 2 contained much fewer impurities than Glycerin 1. Their comparative characteristics are discussed in the following result section.

In this study, the crude glycerin was used as a binder for pelletizing the ground palm fronds. The proximate analysis of the palm fronds and crude glycerin was performed by following the ASTM methods as described in Table 1. These tested properties included a heating value, specific density, moisture content, combustion ash, volatile matter, and fixed carbon. Additionally, the ultimate analysis was performed to determine the typical element contents of the raw materials using an elemental analyzer (Model PE2400 Series II, PerkinElmer Inc., USA). The elements were carbon $(\mathrm{C})$, hydrogen $(\mathrm{H})$, oxygen $(\mathrm{O})$, nitrogen $(\mathrm{N})$, and sulfur (S).

Table 1. Analytical methods for characterizing the raw materials and pelletized fuel.

\begin{tabular}{ll}
\hline Characteristic & Analytical method \\
\hline Heating value & Bomb calorimeter [16] \\
Specific density & Gravimetric method and water replacement $[17]$ \\
Moisture content & Oven-drying of $1 \mathrm{~g}$ of pellet sample at $104-110^{\circ} \mathrm{C}$ for 1 hour [18] \\
Volatile matter content & Pyrolysis of $1 \mathrm{~g}$ of pellet sample at $950^{\circ} \mathrm{C}$ for 9 min $[19]$ \\
Ash content & Furnace-burning of $1 \mathrm{~g}$ of pellet sample at $750^{\circ} \mathrm{C}$ for 1 hour $[20]$ \\
Fixed carbon content & Subtracted quantity with moisture content, volatile matter and ash \\
& contents [21] \\
\hline
\end{tabular}

The pelletized fuel properties were evaluated in similar fashion as the raw materials. We also evaluated the pelletizing efficiency $(P E)$ of the palm frond matrix as defined by the following equation:

$$
P E=\frac{M_{p}}{M_{m}}
$$

where $M_{p}$ is the weight of the complete-shape fuel pellets produced by the pellet press machine used in this study, and $M_{m}$ is the weight of the raw material matrix that was introduced to the pellet press machine.

\subsection{Pelletizing Process and Effects of Influencing Factors}

The glycerin and oil palm fronds were preheated at $90^{\circ} \mathrm{C}$ to soften a lignin component in the fronds, which can act as a natural binder [10]. Both raw materials were then mixed together using a mechanical mixer for $10 \mathrm{~min}$. Consequently, the mixture was pelletized through a pellet press machine equipped with a fixed ring matrix and rotating roller (Model JXKL120, Jingxin Ltd., China). The machine produces cylindrical-shape pellets with a diameter of $6 \mathrm{~mm}$. The fuel briquettes were then oven-dried at $50-60^{\circ} \mathrm{C}$ for 1 day prior to evaluating the fuel properties. Each designed matrix ratio was repeated three times for statistical analyses of the fueling properties.

\subsubsection{Effect of crude glycerin types}

In this test, glycerin was used as a binder for pelletizing the palm fronds. The two types of glycerin from two different biodiesel-processing plants, Glycerin 1 and Glycerin 2, were tested for their effect on the fuel pellet quality. The matrix ratio of oil palm fronds to glycerin was controlled at 70:30 (by wt). No water was added in the matrix. However, the ground fronds contained a moisture content of approximately $7.4 \%$ (Table 2). After pelletizing, the pellet samples were characterized for their fuel properties as described in Table 1.

\subsubsection{Effect of the glycerin contents}

Glycerin 1 was used in this test. The amount of glycerin in the fuel matrix was varied by 19, 22, 26, 29, 32, $35,39,42$, and $45 \%$ on a dry weight basis. Note that the moisture content of the biomass was in the range of 5.4 to $16 \%$. The pellet samples were evaluated for their fuel properties. 


\subsubsection{Effect of glycerin preconditioning}

Glycerin 1 was used in this test, and it had the initial $\mathrm{pH}$ of 8.5 . The glycerin was pretreated by adjusting its $\mathrm{pH}$ to 5,6 , and 7 using a sulfuric acid. The addition of $\mathrm{H}_{2} \mathrm{SO}_{4}$ to Glycerin 1 led to a precipitate, possibly as $\mathrm{Na}_{2} \mathrm{SO}_{4}$. For this test the matrix was composed of the oil palm fronds, precipitate-removed glycerin, and water with the ratio of 60:30:10 (by wt). Note that the addition of 10\% water was to facilitate pressing the mixture through the pellet press machine. The pelletized fuel was then tested for their fuel properties.

\section{Results and Discussion}

\subsection{Characteristics of Raw Materials}

Table 2 presents the results of the proximate and ultimate analyses and heating values of the oil palm fronds and crude glycerin obtained from the two biodiesel-processing plants. The oil palm fronds have a high volatile matter content of $72.5 \%$, but contain a small amount of $5.8 \%$ fixed carbon. This high quantity of volatile matter indicates an inflammable property of the palm frond biomass [22]. The heating value of the palm fronds was found to be $17.2 \mathrm{MJ} / \mathrm{kg}$, which is relatively higher than those of other residual parts of an oil palm tree [14]. However, the oil palm fronds contained an ash content of $14.3 \%$, which is significantly higher than an average of typical biomass of $2.7 \%$ [23]. The element analysis showed that the palm fronds have a smaller amount of sulfur, compared with the lignite coal currently used in Thailand by 25 fold. For the results of glycerin analysis, both glycerin wastes had a high volatile content, but they had no fixed carbon content. With the different biodiesel-processing technologies, Glycerin 1 contained a significantly higher amount of water content than Glycerin 2. It also contained residual methyl esters and carry-over of feedstock oil, which contributed to a greater heating value than Glycerin 2, which had less quantity of impurities. Furthermore, Glycerin 2 exhibited the higher element contents of oxygen and sulfur than Glycerin 1 possibly due to the sulfuric acid treatment.

Table 2. Properties of oil palm fronds and glycerin.

\begin{tabular}{lccc}
\hline Analysis & Oil palm fronds & Glycerin 1 & Glycerin 2 \\
\hline Proximate (\%wt) & & & \\
- Moisture content & 7.4 & 25.1 & 0.6 \\
- Volatile matter & 72.5 & 72.6 & 92.4 \\
- Fixed carbon & 5.8 & 0 & 0 \\
- Ash & 14.3 & 2.3 & 7.0 \\
\hline Ultimate $(\% \mathrm{wt})$ & & & \\
- Carbon & 38.4 & 47.5 & 32.4 \\
- Hydrogen & 5.5 & 9.3 & 6.9 \\
- Oxygen & 32.1 & 15.1 & 43.8 \\
- Nitrogen & 2.3 & 0.6 & 0.4 \\
- Sulfur & 0.09 & 0.03 & 5.30 \\
- Other & 21.61 & 27.47 & 11.2 \\
\hline Heating value $(\mathrm{MJ} / \mathrm{kg})$ & 17.2 & 25.7 & 14.8 \\
\hline
\end{tabular}

\section{2. $\quad$ Effect of Crude Glycerin Types}

The tested fuel briquettes were prepared with the palm fronds to glycerin ratio of 70:30 (by wt). The evaluated properties of the fuel pellets are presented in Table 3. The oil palm fronds are composed of $64.3 \%$ of cellulose, $26.4 \%$ of hemicelluloses, and $6.2 \%$ of lignin. Cellulose is considered as a major source of volatile content in the biomass, while lignin serves as a natural binder in the biomass [8, 24]. However, the oil palm fronds contain relatively low lignin content. Thus, the addition of a binder, like glycerin, is expected to enhance combination of biomass particles. The test results show that both samples containing the two different glycerin types can satisfy the fuel pellet quality demands for domestic use as suggested by the European Biomass Industry Association (EUBIA) for pellet characteristics of the bulk density and moisture content [25]. The finished fuel pellets contained the relatively low moisture contents of 3.2-3.3\% because the pellets were oven-dried at $50-60^{\circ} \mathrm{C}$ for 1 day. Comparing the heat of combustion indicates that 
the pelletized fuel containing Glycerin 1 provided a better fuel quality than the pelletized fuel containing Glycerin 2. As stated previously, Glycerin 1 was simply separated from methyl esters by gravitational settling; thus, it still contained a higher amount of carry-over methyl ester than Glycerin 2. As a result, the fuel containing Glycerin 1 provided a heating value of 1.7 times greater than that containing Glycerin 2. It also had the heating value greater than the suggested EUBIA value of $17 \mathrm{MJ} / \mathrm{kg}$. However, the ash contents of both fuel samples still far exceeded the suggested EUBIA value.

Table 3. Properties of pelletized fuel prepared from palm fronds and two different glycerin types.

\begin{tabular}{|c|c|c|c|c|c|c|c|}
\hline \multirow{2}{*}{$\begin{array}{l}\text { Pelletized } \\
\text { fuel }\end{array}$} & \multirow{2}{*}{$\begin{array}{l}\text { Pelletizing } \\
\text { efficiency } \\
(\%)\end{array}$} & \multirow{2}{*}{$\begin{array}{c}\text { Bulk } \\
\text { density } \\
\left(\mathrm{kg} / \mathrm{m}^{3}\right)\end{array}$} & \multicolumn{4}{|c|}{ Proximate analysis $(\%$ by $w t)$} & \multirow{2}{*}{$\begin{array}{l}\text { Heating } \\
\text { value } \\
\text { (MJ/kg) }\end{array}$} \\
\hline & & & $\begin{array}{c}\text { Moisture } \\
\text { content }\end{array}$ & $\begin{array}{l}\text { Volatile } \\
\text { matter }\end{array}$ & Ash & $\begin{array}{c}\text { Fixed } \\
\text { carbon }\end{array}$ & \\
\hline $\begin{array}{l}\text { Fuel with } \\
\text { Glycerin } 1\end{array}$ & 83 & 996.0 & 3.3 & 82.0 & 13.6 & 1.1 & 19.2 \\
\hline $\begin{array}{l}\text { Fuel with } \\
\text { Glycerin } 2\end{array}$ & 87 & 994.9 & 3.2 & 78.6 & 13.5 & 4.7 & 16.2 \\
\hline EUBIA [23] & & $>650$ & $<10$ & - & $<0.5$ & - & $>17$ \\
\hline
\end{tabular}

\subsection{Effect of Glycerin Contents}

\subsubsection{Pelletizing efficiency}

Figure 1 shows the effect of the glycerin contents, ranging from 19 to $45 \%$, on the pelletizing efficiency of the palm frond matrix. An uncertainty range shown is based on \pm one standard deviation from the measured values of the three sampling pellets. Note that the pelletizing efficiency values were calculated according to Eq. (1). The matrix containing glycerin below $19 \%$ cannot be formed into a pellet due to its friability. It becomes dislodged after being removed from the mould. However, the pelletizing efficiency tended to slightly decrease when the glycerin content was increased. The high glycerin content caused the loose combination of the biomass and glycerin particles making the pelletized fuel become soft. Increasing the glycerin content over 50\% resulted in very loosely packed pellets. Figure 2 (a)-(c) shows the physical appearance of the pelletized fuel containing various amounts of glycerin, i.e., $19 \%, 35 \%$, and $45 \%$, respectively, after oven-drying for 1 day. The pellet containing $19 \%$ glycerin had a smooth surface without cracks, while the pellets with the higher amounts of glycerin appeared to have a rough surface and some cracks.

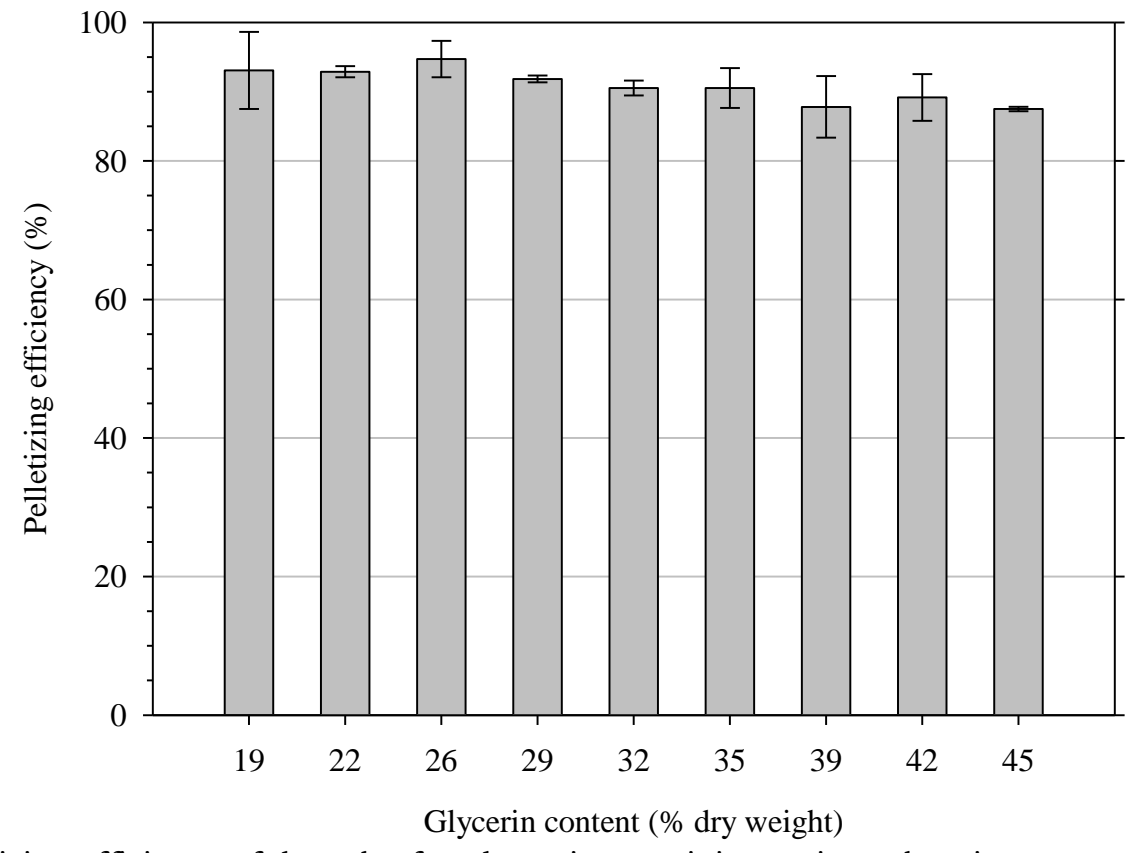

Fig. 1. Pelletizing efficiency of the palm frond matrix containing various glycerin contents. 

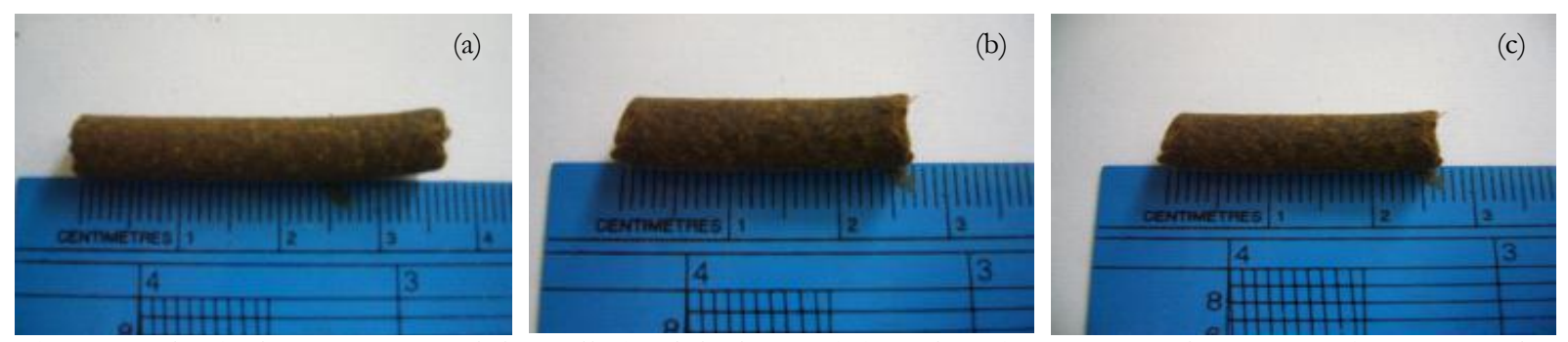

Fig. 2. Physical appearance of the pelletized fuel containing glycerin amount of: (a) $19 \%$, (b) $35 \%$, and (c) $45 \%$ by dry weight.

In this study, the moisture content of the raw material matrix was at $5.4-16 \%$. This range of the moisture content was a result of controlling the studied glycerin content of $19-45 \%$. Figure 1 suggests that this moisture range seems not to have the effect on pelletizing the palm fronds and glycerin mixture. A similar study conducted by Razuan et al. [10] reported that a good quality pellet was obtained from 2-mm palm kennel cake with the moisture content of $7.9 \%$, an "as received level". A high moisture level up to $15 \%$ caused the pellets to collapse immediately when ejected from the mould, while a low moisture content of 5\% caused the pellets to crack instantly. However, they were unable to establish a relationship between the moisture contents and pellet quality in the range of 7.9 to $15 \%$. Another study on fuel pelletizing from hay compaction was tested at the relatively high moisture contents of $28-44 \%$ (by wt). The result indicated that increasing the moisture content can decrease the density of the pelletized fuel [26]. It is likely that the moisture contents of $5.4-16 \%$ applied to the studied pellets were not low or high enough to cause the pellets to crack or collapse.

\subsubsection{Heating value}

Figure 3 shows association of the heating values of the pelletized fuel containing various amounts of glycerin contents. Note that the heating value was determined by the Bomb calorimetric method. The Bomb calorimetric method yielded a similar heating value to the estimated value from the individual heating values of the palm frond and glycerin contents in the matrix. The linear regression modeling the relationship yields the $R^{2}$ of 0.839 at the significant level of 0.001 . An increase of the glycerin content from $19 \%$ to $45 \%$ can increase the combustion heating value from 17.8 to $20.5 \mathrm{MJ} / \mathrm{kg}$ or by $15 \%$. The glycerin itself has a greater heating content than the palm fronds. Thus, use of glycerin as a binder helps to improve the biomass pelletized fuel for its calorific property.

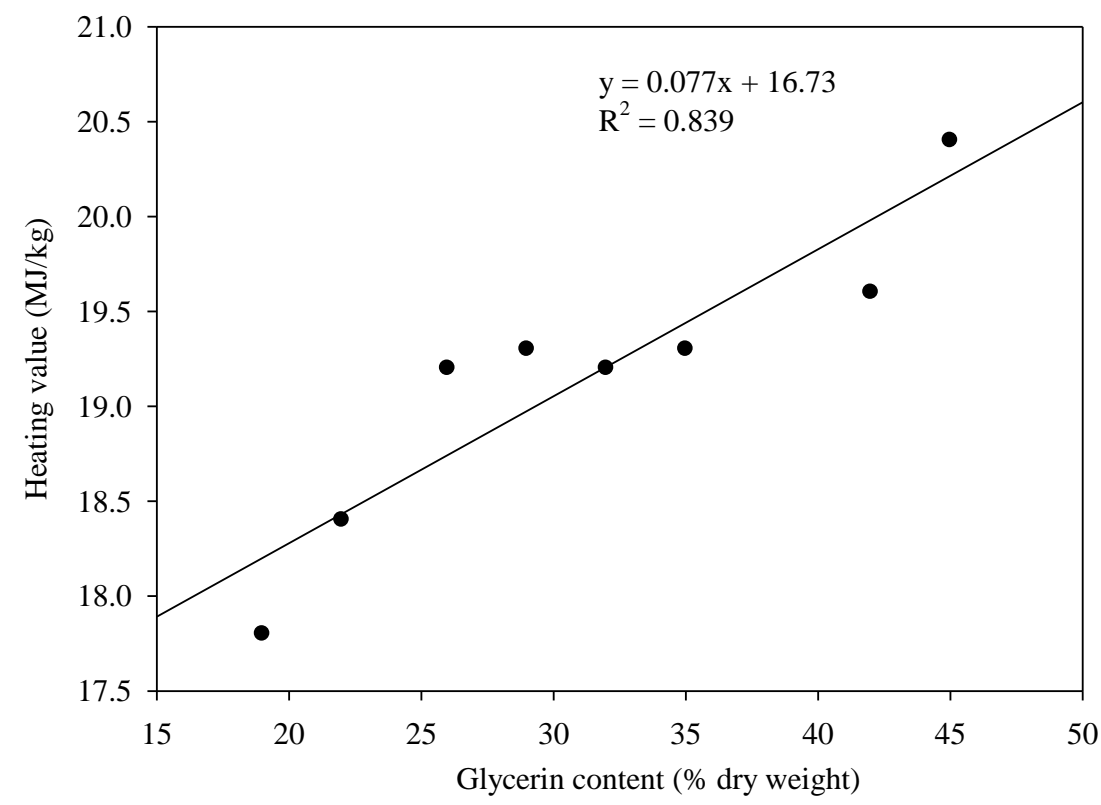

Fig. 3 Relationship between the glycerin contents and heating value of the pelletized fuel containing 19$45 \%$ glycerin contents. 


\subsubsection{Pelletized fuel quality}

Table 4 presents the bulk density, the proximate analysis results, and the heating value for the pelletized fuel as well as the pellet quality demands suggested by EUBIA [25]. All tested properties of the studied fuel pellets were found to comply with the suggested values, except for the ash content. The combustion of the oil palm fronds yielded the ash content up to $14.3 \%$, while the ash content from burning Glycerin 1 was only $2.3 \%$ (Table 2). Thus, an increase of glycerin in the palm frond matrix appears to benefit the reduction of the ash content of the fuel. However, the maximum glycerin of $45 \%$ still produced an amount of ash greater than the criterion value of $0.5 \%$.

Table 4. Properties of pelletized fuel containing various glycerin contents.

\begin{tabular}{|c|c|c|c|c|c|c|}
\hline \multirow[b]{2}{*}{$\begin{array}{l}\text { Glycerin } \\
\text { content }(\%)\end{array}$} & \multirow[b]{2}{*}{$\begin{array}{l}\text { Bulk density } \\
\left(\mathrm{kg} / \mathrm{m}^{3}\right)\end{array}$} & \multicolumn{4}{|c|}{ Proximate analysis $(\% \mathrm{wt})$} & \multirow{2}{*}{$\begin{array}{l}\text { Heating } \\
\text { value } \\
\text { (MJ/kg) }\end{array}$} \\
\hline & & $\begin{array}{c}\text { Moisture } \\
\text { content }\end{array}$ & $\begin{array}{l}\text { Volatile } \\
\text { matter }\end{array}$ & Ash & $\begin{array}{l}\text { Fixed } \\
\text { carbon }\end{array}$ & \\
\hline 19 & $996.6 \pm 0.5$ & $4.12 \pm 1.32$ & $77.4 \pm 0.2$ & $16.0 \pm 0.3$ & $2.47 \pm 1.21$ & $17.8 \pm 0.0$ \\
\hline 22 & $995.7 \pm 0.3$ & $3.99 \pm 1.56$ & $80.8 \pm 2.7$ & $15.0 \pm 0.5$ & $0.23 \pm 1.26$ & $18.4 \pm 0.0$ \\
\hline 26 & $996.0 \pm 0.5$ & $3.33 \pm 1.60$ & $82.0 \pm 2.8$ & $13.6 \pm 1.2$ & $1.09 \pm 2.65$ & $19.2 \pm 0.1$ \\
\hline 29 & $997.8 \pm 2.2$ & $2.12 \pm 0.12$ & $83.1 \pm 2.9$ & $12.5 \pm 2.5$ & $2.31 \pm 2.13$ & $19.3 \pm 0.0$ \\
\hline 32 & $997.1 \pm 1.2$ & $2.68 \pm 0.13$ & $81.3 \pm 6.1$ & $14.1 \pm 0.3$ & $2.08 \pm 5.95$ & $19.2 \pm 0.0$ \\
\hline 35 & $995.7 \pm 0.0$ & $3.58 \pm 0.13$ & $79.6 \pm 1.2$ & $12.9 \pm 1.4$ & $3.93 \pm 2.50$ & $19.3 \pm 0.1$ \\
\hline 42 & $995.5 \pm 0.2$ & $4.03 \pm 0.19$ & $81.8 \pm 2.9$ & $12.7 \pm 1.4$ & $1.41 \pm 2.04$ & $19.6 \pm 0.0$ \\
\hline 45 & $994.0 \pm 8.4$ & $4.35 \pm 0.07$ & $81.3 \pm 2.7$ & $11.9 \pm 0.1$ & $2.38 \pm 2.60$ & $20.4 \pm 0.0$ \\
\hline EUBIA [25] & $>650$ & $<10$ & - & $<0.5$ & - & $>17$ \\
\hline
\end{tabular}

In this test, Glycerin 1 obtained from the biodiesel plant was contaminated with $\mathrm{NaOH}$ because it is used in a tranesterification for the biodiesel production. Increasing the glycerin content over $26 \%$ seems to affect the pelletizing efficiency of the palm frond matrix as shown in Fig. 1. Razuan et al. [10] reported that the addition of $\mathrm{NaOH}$ as a binder can increase the tensile strength of the pelletized fuel from palm kennel cake. They contributed this effect to the ability of $\mathrm{NaOH}$ to bind the biomass particles together. However, the further addition of $\mathrm{NaOH}$ over $2.0 \%$ (by wt) reduced the tensile strength. As a result, they suggested limiting the amount of $\mathrm{NaOH}$ used to $1.5-2.0 \%$ (by wt). For the chemical composition analysis of the ash from the palm frond fuel containing $26 \%$ glycerin (Table 5), it was composed of the high amounts of $72.9 \%$ $\mathrm{SiO}_{2}$ and $13.5 \% \mathrm{CaO}$ and other alkali metal contents such as $3.58 \% \mathrm{~K}_{2} \mathrm{O}$ and $2.62 \% \mathrm{Na}_{2} \mathrm{O}$ due to the contamination with $\mathrm{NaOH}$. Comparing the ash chemical properties with the ASTM standard specification for pozzolans suggests a potential use of the palm frond/glycerin fuel ash in concrete [27].

Table 5. Chemical compositions of ash from combustion of pelletized fuel containing $74 \%$ oil palm fronds and $26 \%$ glycerin.

\begin{tabular}{|c|c|c|c|c|c|c|c|c|c|c|}
\hline \multirow{2}{*}{ Material } & \multicolumn{10}{|c|}{ Ash composition (\%) } \\
\hline & $\mathrm{Na}_{2} \mathrm{O}$ & $\mathrm{Al}_{2} \mathrm{O}_{3}$ & $\mathrm{SiO}_{2}$ & $\mathrm{Fe}_{2} \mathrm{O}_{3}$ & $\mathrm{SO}_{3}$ & $\mathrm{MgO}$ & $\mathbf{P}_{2} \mathbf{O}_{5}$ & $\mathrm{CaO}$ & $\mathrm{MnO}_{2}$ & $\mathrm{~K}_{2} \mathrm{O}$ \\
\hline $\begin{array}{l}\text { Pelletized } \\
\text { fuel }\end{array}$ & 2.62 & 0.21 & 72.9 & 0.95 & 0.35 & 1.95 & 1.98 & 13.5 & 1.61 & 3.58 \\
\hline $\begin{array}{l}\text { Pozzolans } \\
{[27]}\end{array}$ & - & $\mathrm{Al}_{2} \mathrm{C}$ & $\begin{array}{l}\mathrm{SiO}_{2}+ \\
>70\end{array}$ & $\mathrm{e}_{2} \mathrm{O}_{3}$ & $<4.0$ & - & - & - & - & - \\
\hline
\end{tabular}

\subsection{Effect of Glycerin Preconditioning}

It should be noted that the initial $\mathrm{pH}$ of Glycerin 1 was 8.5 . The $\mathrm{pH}$ of the glycerin was then adjusted to 5 , 6 , and 7 using a sulfuric acid prior to mixing with the ground palm fronds. Table 6 presents the properties of the preconditioned-glycerin/palm frond fuel pellets. The $\mathrm{pH}$-adjusted glycerin appeared to reduce the pelletizing efficiency of the palm frond matrix, comparing with the unconditioned-glycerin fuel sample. This could be due to the less amount of $\mathrm{NaOH}$ in the reduced-pH glycerin. However, it is still unclear why the conditioned glycerin with $\mathrm{pH}$ of 5 and 6 yielded the higher pelletizing efficiency than did the neutraladjusted glycerin. Unfortunately, the $\mathrm{NaOH}$ and sodium element contents of the pelletized fuel specimens 
with conditioned and unconditioned glycerin types were not determined in this study. For the heating property, the unconditioned and conditioned glycerin binders yielded the pelletized fuel with relatively similar heating values. Thus, the $\mathrm{pH}$ preconditioning of the glycerin may not assist in significantly improving the fuel quality of the palm frond pelletized fuel. Comparing with pelletized fuel containing Glycerin 2 that was undergone the acid treatment at the biodiesel plant, the $\mathrm{pH}$-adjusted Glycerin 1 still provided the greater calorific value for the fuel pellets (Table 3). This may be because of the residual methyl esters in Glycerin 1.

Table 6. Properties of pelletized fuel with $\mathrm{pH}$-preconditioning of glycerin.

\begin{tabular}{|c|c|c|c|c|c|c|c|}
\hline \multirow[b]{2}{*}{$\begin{array}{l}\mathrm{pH} \text { of } \\
\text { glycerin }\end{array}$} & \multirow{2}{*}{$\begin{array}{l}\text { Pelletizing } \\
\text { efficiency } \\
(\%)\end{array}$} & \multirow[b]{2}{*}{$\begin{array}{c}\text { Bulk density } \\
\left(\mathrm{kg} / \mathrm{m}^{3}\right)\end{array}$} & \multicolumn{4}{|c|}{ Proximate analysis $(\% \mathrm{wt})$} & \multirow{2}{*}{$\begin{array}{c}\text { Heating } \\
\text { valuet } \\
\text { (MJ } / \mathrm{kg} \text { ) }\end{array}$} \\
\hline & & & $\begin{array}{c}\text { Moisture } \\
\text { content }\end{array}$ & $\begin{array}{c}\text { Volatile } \\
\text { matter }\end{array}$ & Ash & $\begin{array}{l}\text { Fixed } \\
\text { carbon }\end{array}$ & \\
\hline 5 & 86.8 & $995.7 \pm 0.3$ & $1.13 \pm 0.15$ & $79.0 \pm 0.3$ & $13.9 \pm 0.4$ & $5.91 \pm 0.00$ & 20.2 \\
\hline 6 & 83.1 & $995.2 \pm 0.2$ & $1.36 \pm 0.12$ & $79.5 \pm 3.4$ & $13.9 \pm 0.4$ & $5.27 \pm 3.55$ & 20 \\
\hline 7 & 78.1 & $995.2 \pm 0.3$ & $1.37 \pm 0.14$ & $82.9 \pm 2.5$ & $13.8 \pm 0.0$ & $1.91 \pm 2.71$ & 21.7 \\
\hline $8.5^{*}$ & 91.8 & $997.8 \pm 2.2$ & $2.12 \pm 0.12$ & $83.1 \pm 2.9$ & $12.5 \pm 2.5$ & $2.31 \pm 2.13$ & 19.3 \\
\hline
\end{tabular}

${ }^{*}$ Pelletized fuel containing the crude glycerin without $\mathrm{pH}$ adjustment.

${ }^{\dagger}$ Values were determined from one sample or one trial.

\subsection{Economic Evaluation}

A preliminary economic evaluation of the expected production cost for the palm frond/glycerin pelletized fuel mainly includes the electricity cost from a grinder, mechanical mixer, pellet press machine, and heating oven. In this calculation, costs for purchasing oil palm fronds and crude glycerin are excluded because the crude glycerin from most large-scale biodiesel plants in Thailand is currently disposed of with certain expense. Thus, the production cost of the palm frond/glycerin pelletized fuel is attributed to only operational cost. Production of one ton of the fuel pellets costs approximately 1890 baht or 60 USD. The cost is close to the lignite cost in Thailand. Comparing the production cost per heating value with other biomass and fossil fuels reveals $0.094 \mathrm{baht} / \mathrm{MJ}$ for the palm frond/glycerin pelletized fuel, 0.027-0.047 baht/MJ for rice husk, saw dust, woodchips and palm shell [28], and $0.341 \mathrm{baht} / \mathrm{MJ}$ for fuel oil [15]. Obviously, the cost of the palm frond/glycerin pelletized fuel is 2-3 times higher than the typical biomass fuels because of an addition of the operational cost for pelletization. However, the palm frond/glycerin pellets cost 3 times less than fuel oil.

\section{Conclusions}

Oil palm fronds and crude glycerin, which are an agricultural residue and by-products from a biodieselprocessing production, are experimentally proven to be promising raw materials for producing fuel pellets. The production of the palm frond/glycerin pellets can also promote a zero waste approach for the biodiesel-processing industry and can eliminate disposal cost of the crude glycerin. The combination of the ground palm fronds and glycerin content with 19-45\% (by wt) can be pelletized, providing the heating value of 17.8-20.4 MJ $/ \mathrm{kg}$. This pelletized fuel exhibits a higher calorific value than conventional biomass and lignite coal currently used in Thailand. The crude glycerin obtained from the community-scale biodiesel plant using a batch mode appears to provide the pelletized fuel with a greater heating value than that containing the less contaminated glycerin. The preconditioning of the glycerin with $\mathrm{pH}$ adjustment does not significantly affect the fuel quality of the pellets. Although the properties of the palm frond/glycerin fuel pellets meet the fuel pellet quality demands suggested by EUBIA, the combustion ash content still exceeds the suggested value. Thus, improvement of the palm frond/glycerin fuel pellets is further needed for commercial production. For replacement of or as a supplement to gas or oil fired furnaces and boilers, the palm frond/glycerin pellets could be used along with other typical biomass fuels such as woodchips. This fuel mixture is expected to effectively provide heat as well as maintain a fire. However, there is a concern of toxic gas emissions from burning glycerin such as acrolein [29]. To avoid this problem, the palm frond/glycerin pellets should be combusted in a high-temperature environment with a proper glycerin-air mixture. 


\section{Acknowledgements}

This research was financially supported by the Graduate School of Chulalongkorn University and the Energy Policy and Planning Office, Ministry of Energy, Royal Thai Government. This material was based upon work supported by Thai Government Stimulus Package 2 (TKK2555) under the project for promotion of bio and biomass utilization potential for fuel production and exporting technology, Chulalongkorn University.

\section{References}

[1] J. B. Gonsalves, "An assessment of the biofuels industry in Thailand," in Conference on Trade and Development, United Nations, Geneva, Switzerland, 2006.

[2] DEDE. (2009). Potential of Biomass in Thailand. Department of Alternative Energy Development and Efficiency, Ministry of Energy, Thailand. [Online.] Available: http://www.dede.go.th/dede/ index.php?option $=$ com_content\&view $=$ article\&id $=130: 2010-05-07-08-10-57 \&$ catid $=58 \&$ Itemid $=68$

[3] O. O. Fasina, "Physical properties of peanut hull pellets," Bioresource Technol., vol. 99, pp. 1259-1266, 2007.

[4] D. Bergström, S. Israelsson, M. Öhman, S. -A. Dahlqvist, R. Gref, C. Boman, and I. Wästerlund, "Effects of raw material particle size distribution on the characteristics of Scots pine saw dust fuel pellets," Fuel Process Technol., vol. 89, pp. 1324-1329, 2008.

[5] A. B. Nasrin, A. N. Ma, S. Mohamad, M. H. Rohaya, A. Azali, and Z. Zainal, "Oil palm biomass as potential substitution raw materials for commercial biomass briquettes production," Am. J. Appl. Sci., vol. 5, pp. 179-183, 2008.

[6] S. Mani, L. G. Tabil, and S. Sokhansanj, "Effects of compressive force, particle size and moisture content on mechanical properties of biomass pellets from grasses," Biomass Bioenerg., vol. 30, pp. 648654, 2006.

[7] C. Ryu, K. Finney, V. N, Sharifi, and J. Swithenbank, "Pelletised fuel production from coal tailings and spent mushroom compost - Part I: Identification of pelletisation parameters," Fuel Process Technol., vol. 89, pp. 269-275, 2008.

[8] A. K. Biswas, W. Yang, and W. Blasiak, "Steam pretreatment of Salix to upgrade biomass fuel for wood pellet production," Fuel Process Technol., vol. 92, pp. 1711-1717, 2011.

[9] M. L. Kubacki, A. B. Ross, J. M. Jones, and A. Williams, "Small-scale co-utilisation of coal and biomass," Fuel, vol. 101, pp. 84-89, 2012.

[10] R. Razuan, K. N. Finney, Q. Chen, V. N. Sharifi, and J. Swithenbank, "Pelletised fuel production from palm kernel cake," Fuel Process Technol., vol. 92, pp. 609-615, 2011.

[11] W. Stelte, J. K. Holm, A. R. Sanadi, S. Barsberg, J. Ahrenfeldt, and U. B. Henriksen, "Fuel pellets from biomass: The importance of the pelletizing pressure and its dependency on the processing conditions," Fuel, vol. 90, pp. 3285-3290, 2011.

[12] T. Raghareutai, O. Chavalparit, and M. Ongwandee, "Development of environmental sustainability for the biodiesel industry in Thailand," Int. J. Sust. Dev. World, vol. 17, pp. 363-369, 2010.

[13] DEDE. (2008). Thailand energy situation 2008. Department of Alternative Energy Development and Efficiency, Ministry of Energy, Thailand. [Online]. Available: http://www.dede.go.th/dede/ fileadmin/upload/nov50/feb52/re1_pre_ener_2551.pdf

[14] DEDE. (2008). Biomass. Department of Alternative Energy Development and Efficiency, Ministry of Energy, Thailand. [Online]. Available http://www2.dede.go.th/renew/bio_p.htm

[15] EPPO. (2009). Oil price situation 2009. Energy Policy and Planning Office, Ministry of Energy, Thailand. [Online]. Available http://www.eppo.go.th/petro/report/price-2552-09-14-20.pdf

[16] ASTM, "Standard test method for gross calorific value of coal and coke by microprocessor controlled isoperibol calorimeters," American Society for Testing and Materials, PA, USA, ASTM D1989 - 97, 1997.

[17] F. Rabier, M. Temmerman, T. Böhm, H. Hartmann, P. D. Jensen, J. Rathbauer, J. Carrasco, and M. Fernández, "Particle density determination of pellets and briquettes," Biomass Bioenerg., vol. 30, pp. 954-963, 2006.

[18] ASTM, "Standard Test method for moisture in the analysis sample of coal and coke," American Society for Testing and Materials, PA, USA, ASTM D3173 - 03, 2003. 
[19] ASTM, "Standard test method for volatile matter in the analysis sample of coal and coke," American Society for Testing and Materials, PA, USA, ASTM D3175 - 07, 2007.

[20] ASTM, "Standard test method for ash in the analysis sample of coal and coke from coal," American Society for Testing and Materials, PA, USA, ASTM D3174 - 04, 2004.

[21] ASTM, "Standard practice for proximate analysis of coal and coke," American Society for Testing and Materials, PA, USA, ASTM D3172 - 07a, 2007.

[22] S. Mungmeesithi. (2011). Construction of biomass cooking stoves for community. Research and Development Institute of Silpakorn University. [Online]. Available: http://www.surdi.su.ac.th/paper_public/ Biomass-new.pdf

[23] S. V. Vassilev, D. Baxter, L. K. Anderson, and C. G. Vassileva, "An overview of the chemical composition of biomass," Fuel, vol. 89, pp. 913-933, 2010

[24] Wahyudiono, S. Machmudah, and M. Goto, "Utilization of sub and supercritical water reactions in resource recovery of biomass wastes," Engineering Journal, vol. 17, pp. 1-12, 2013.

[25] EUBIA. (2007). Comparison between briquettes and pellets. European Biomass Industry Association. [Online]. Available http://www.eubia.org/197.0.html.

[26] A. S. Gustafson and W. L. Kjelgaard, "Hay pellet geometry and stability," Agricultural Engineering, vol. 44, pp. 442-445, 1963.

[27] ASTM, "Standard specification for coal fly ash and raw or calcined natural pozzolan for use in concrete," American Society for Testing and Materials, PA, USA, ASTM C618 - 03, 2003.

[28] DEDE. (2007). A study and Potential Assessment of Biomass Sources. Department of Alternative Energy Development and Efficiency, Ministry of Energy, Thailand.

[29] EPA. (2003). Toxicological Review of Acrolein. US Environmental Protection Agency, Washington, DC EPA/635/R-03/003. 